\title{
Pulp Fibroblasts Synthesize Functional Complement Proteins Involved in Initiating Dentin-Pulp Regeneration
}

\author{
Fanny Chmilewsky, * Charlotte Jeanneau, * Patrick Laurent, ${ }^{* \dagger}$ and Imad About*

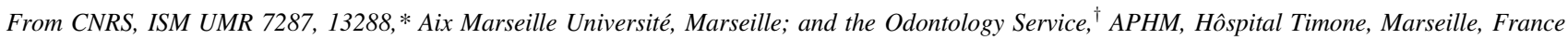

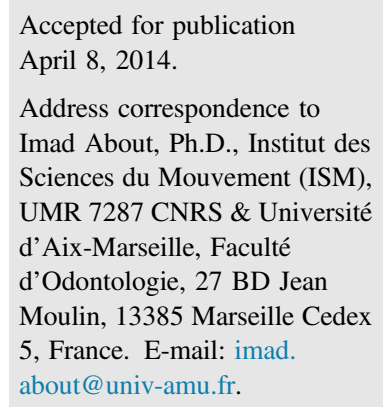

\begin{abstract}
The complement system is an efficient plasma immune surveillance system that controls tissue injury and infection. Although the liver constitutes the primary circulating complement protein synthesis site, extrahepatic synthesis is known to optimize local tissue inflammatory reaction. Because dentin-pulp regeneration is known to be regulated locally, we investigated activation of the local complement system within the dental pulp and its role in initiating the regeneration process. Membrane attack complex (C5b-9) formation and Gram's staining revealed that complement activation is correlated with the presence of Gram-positive bacteria in carious human teeth. RT-PCR analysis demonstrated that cultured human pulp fibroblasts stimulated with lipoteichoic acid produce all the proteins required for efficient complement activation. This was demonstrated in vitro by $\mathrm{C} 5 \mathrm{~b}-9$ formation and $\mathrm{C} 5 \mathrm{a}$ active fragment production in the absence of plasma proteins. Finally, the dynamic migration assays performed in $\mu$-Slide chemotaxis chambers and use of a C5aR-specific antagonist (W54011) demonstrated that the activation of complement proteins synthesized by pulp fibroblasts and the subsequent release of C5a specifically induced pulp progenitor cell recruitment. Our study reveals human pulp fibroblasts as the first nonimmune cell type capable of synthesizing all complement proteins. These fibroblasts cells contribute significantly to tissue regeneration by recruiting pulp progenitors via complement activation, which suggests to a potential therapeutic strategy of targeting pulp fibroblasts in dentin-pulp regeneration. (Am J Pathol 2014, 184: 1991-2000; http://dx.doi.org/10.1016/j.ajpath.2014.04.003)
\end{abstract}

The complement system is as a rapid and efficient plasma immune surveillance system to control tissue injury and infection that regulates the inflammatory process, clearance of necrotic and apoptotic cells, and tissue regeneration. ${ }^{1-3}$ The complement system is quickly activated by three principal enzymatic cascades, the classical, lectin, and alternative pathways, which converge into a terminal pathway that leads to deposition of the membrane attack complex (MAC)/C5b-9 on cell and pathogen surfaces. ${ }^{3,4}$ The liver is the primary site for synthesis of circulating complement proteins (except for C1q, C7, and factor D). ${ }^{5,6}$ However, a wide range of soluble proteins of the complement system seem to be secreted from a variety of organs, tissues, and cells, either constitutively or as a response to various stimuli. ${ }^{7}$ This extrahepatic synthesis, which generates a basal and local pool of complement molecules, represents a significant contribution to local tissue inflammatory reaction. ${ }^{7}$ Complement activation can be induced by bacterial infection, the presence of apoptotic and necrotic cells, or biomaterial-modified surfaces. ${ }^{8-11}$ All of these events are well represented during dental pulp injuries and tooth restorative procedures.

Dentin is a hard tissue secreted by postmitotic cells called odontoblasts. During the carious process, this hard tissue, which protects the underlying pulp, is subject to demineralization by acids produced by multiple pathogens (predominantly Gram-positive bacteria). ${ }^{12}$ Under moderate carious lesions affecting the dentin, the secretory activity of the odontoblasts is stimulated to locally elaborate a protective layer of reactionary dentin facing the carious site. By contrast, deep cavity preparation during restorative procedures and deep carious injuries lead to odontoblast disintegration. ${ }^{13,14}$ Under these conditions, pulp progenitor cells are activated and migrate to the injury site, where they regenerate a

Supported by institutional grants from Aix-Marseille University and CNRS and the European Society of Endodontology annual research grant (2012-121 to I.A.).

Disclosures: None declared. 
protective layer of reparative dentin. This migration is critical in initiating dentin-pulp regeneration. ${ }^{15,16}$

Several lines of evidence suggest that dentin-pulp regeneration in the case of carious injuries is regulated locally, by dentin extracellular matrix molecules or by growth factors such as transforming growth factor $\beta 1$ (TGF- $\beta 1$ ) or basic fibroblast growth factor (FGF-2) liberated after an acid dissolution of the carious dentin. ${ }^{14,17,18}$ This can also be the result of release of these growth factors from pulp fibroblasts and endothelial cells in the case of traumatic injuries or after interaction of pulp cells with biomaterials. ${ }^{19-22}$ Recently, it has been demonstrated that carious injury, which is the most common human pathology, activates the complement system. ${ }^{23}$ This activation seems to be implicated in the process of dentin-pulp regeneration. Recombinant complement C5a fragment induces the recruitment of human pulp progenitor STRO $-1^{+}$cells, which express the C5a receptor. ${ }^{23}$ These data were the basis of our hypothesis that pulp complement activation may be regulated locally within the dental pulp.

We investigated the role of the complement system in the interaction between pulp progenitor and nonprogenitor cells during the regenerative process, which occurs under carious injuries affecting odontoblast survival. Our results show, for the first time, that when pulp fibroblasts are subjected to Gram-positive bacteria motif they are able to produce all complement components required for efficient complement activation. The activation of complement proteins from pulp fibroblasts and subsequent $\mathrm{C} 5 \mathrm{a}$ fragment release in the absence of plasma proteins induces pulp progenitor cell recruitment, which is critical in initiating the regenerative processes after dentin-pulp injury.

\section{Materials and Methods}

\section{Materials}

Cell culture materials and reagents were from PAA Laboratories (Les Mureaux, France). Primary antibodies and C5a were from R\&D Systems (R\&D Systems, Lille, France; Minneapolis, MN) or from Abcam (Paris, France; Cambridge, UK). Secondary antibodies were from (Life Technologies, Saint-Aubin, France; Carlsbad, CA). Chemicals were from Carlo Erba Reagents (Val-de-Reuil, France).

\section{Collection of Molar Teeth}

Human immature third molars freshly extracted for orthodontic reasons and carious teeth were obtained in compliance with French legislation (including informed consent and institutional review board approval of the protocol used). Teeth were fixed and routinely processed as described previously. ${ }^{16}$

\section{Immunohistochemistry}

Before tooth sections were stained, antigen retrieval was performed at $98^{\circ} \mathrm{C}$ for 30 minutes in $1 \mathrm{mmol} / \mathrm{L}$ Tris -0.1
Table 1 Primers Used for Complement Component Gene Expression by RT-PCR

\begin{tabular}{|c|c|}
\hline Primer & Sequence \\
\hline $\mathrm{C} 1 \mathrm{q}-1$ & $5^{\prime}-$ CAGGGATAAAAGGAGAGAAAGG- $3^{\prime}$ \\
\hline $\mathrm{C} 1 \mathrm{q}-2$ & 5'-TGGCGTGGTAGGTGAAGTAGTA-3' \\
\hline $\mathrm{C} 1 \mathrm{r}-1$ & $5^{\prime}$-GATCTATGCCAACGGGAAGA-3' \\
\hline $\mathrm{C} 1 \mathrm{r}-2$ & 5'-САТTCTTCCAAАTGCCCTGT-3' \\
\hline C1s-1 & 5'-AAGAGCGTTTTACGGGGTTT-3' \\
\hline $\mathrm{C} 1 \mathrm{~s}-2$ & $5^{\prime}$-ААТСТССССААTCAGTGCAG- $3^{\prime}$ \\
\hline $\mathrm{C} 2-1$ & $5^{\prime}-$ CCTTGAATGGGAGCAAACTGAAC $-3^{\prime}$ \\
\hline $\mathrm{C} 2-2$ & 5'-GATTGATGTGAAAGTCTCGTGGC-3' \\
\hline C3-1 & 5'-GCTGCTCCTGCTACTAACCCA-3' \\
\hline $\mathrm{C} 3-2$ & 5'-AAAGGCAGTTCCCTCCACTTT-3' \\
\hline C4-1 & 5'-TGCGGATCCAGCAGTTTCGG-3' \\
\hline $\mathrm{C} 4-2$ & 5'-TGGCGGTTGTTCAGCTGCAG-3' \\
\hline FB-1 & $5^{\prime}$-GTGTGACCACCACTCCATGG-3' \\
\hline FB-2 & $5^{\prime}-$ CCATCCTCAGCATCGACTCC-3' \\
\hline MASP1-1 & $5^{\prime}$-GCTGGAGGCTCTCATACAGG-3' \\
\hline MASP1-2 & $5^{\prime}-$ ACGTCCCATCCTTCAGACAC- $3^{\prime}$ \\
\hline MASP2-1 & 5'-GCTCCGACTACTCCAACGAG-3' \\
\hline MASP2-2 & $5^{\prime}$-GGCTGATGCTGTAAGTGCAA- $3^{\prime}$ \\
\hline FD-1 & $5^{\prime}$-CGACCACGACCTCCTGCTGCTACA-3' \\
\hline FD-2 & 5'-GCTCGGGACTTTGTTGCTTGGGTG-3' \\
\hline C5-1 & $5^{\prime}$-AGTGTGTGGAAGGGTGGAAG- $3^{\prime}$ \\
\hline C5-2 & 5'-GTTCTCTCGGGCTTCAACAG-3' \\
\hline C6-1 & 5'-TGGGGTCTTGAAAGGACAAG- $3^{\prime}$ \\
\hline C6-2 & 5'-GAGTTGGTTTCCACCCTTGA-3' \\
\hline C7-1 & $5^{\prime}-$ AAAATGCCCTACGAATGTGG - $3^{\prime}$ \\
\hline C7-2 & $5^{\prime}-\mathrm{AAACCCTTCTTCCTCGCACT-3'}$ \\
\hline $\mathrm{c} 8 \alpha-1$ & $5^{\prime}$-CGGTATACAATGGGGAATGG- $3^{\prime}$ \\
\hline$C 8 \alpha-2$ & $5^{\prime}$-GCAGTCTGCACCTTTGTGAA-3' \\
\hline $\mathrm{C} 8 \beta-1$ & $5^{\prime}-$ CAAAGAGGCCATGGAGAGAG- $3^{\prime}$ \\
\hline $\mathrm{C} 8 \beta-2$ & 5'-TGCTTCATGTTCTGCCTCAC-3' \\
\hline $\mathrm{C} 8 \gamma-1$ & 5'-CCAGAGTTTCGCTGTCCTGT-3' \\
\hline $\mathrm{C} 8 \gamma-2$ & 5'-ССТСАССТССТСАСТTCGTC-3' \\
\hline C9-1 & 5'-CAACTGGGCCTCTTCCATAA-3' \\
\hline C9-2 & 5'-CACAGGCAATTCCCTCAAAT- $3^{\prime}$ \\
\hline MBL-1 & $5^{\prime}$-ATGGTGATACTAGCCTGGCT-3' \\
\hline MBL-2 & $5^{\prime}$-ATCCATGATACCCAGGAAGGC-3' \\
\hline GAPDH-1 & 5'-GAAGGTGAAGTTCGGAGTC-3' \\
\hline GAPDH-2 & $5^{\prime}$-GAAGATGGTGATGGGATTTC-3' \\
\hline
\end{tabular}

$\mathrm{mmol} / \mathrm{L}$ EDTA $-0.5 \%$ Tween, and nonspecific binding sites were blocked with $0.25 \%$ casein-PBS for 15 minutes at room temperature. Tooth sections from intact and carious teeth were incubated for 1 hour at room temperature with 50 $\mu \mathrm{g} / \mathrm{mL}$ rabbit anti-human C5b-9 $\operatorname{IgG}$ or control $\mathrm{IgG}$, and then were incubated for 30 minutes with Alexa Fluor 488 goat anti-rabbit $(2 \mu \mathrm{g} / \mathrm{mL})$ and DAPI counterstain $(1 \mu \mathrm{g} / \mathrm{mL})$.

Intact and carious tooth sections were stained using a tissue Gram stain kit (Sigma-Aldrich, St. Louis, MO) according to the manufacturer's instructions.

\section{Primary Pulp Cell Cultures}

Human pulp cells were prepared from immature third molars at the $2 / 3$ root formation stage by the explant outgrowth method. ${ }^{24}$ The teeth were obtained from at least three different donors for each experiment (four molars per donor). 


\section{Magnetic Cell Sorting}

Pulp progenitor cells were directly sorted from primary pulp cell cultures at passages 1 to 5 with mouse anti-human STRO-1 IgM with immune magnetic beads according to the manufacturer's protocol (Dynal Biotech, Oslo, Norway).

\section{RT-PCR}

Total RNAs were isolated cells using a PureLink RNA mini kit (Life Technologies, Oslo, Norway). RNA samples ( $2 \mu \mathrm{g})$ were reverse-transcribed using a reverse transcription AMV system (Promega, Madison, WI). Primer sequences are listed in Table 1. PCR conditions were $95^{\circ} \mathrm{C}$ for 5 minutes, ( 30 cycles of $95^{\circ} \mathrm{C}$ for 30 seconds, $55^{\circ} \mathrm{C}$ for 30 seconds, and $72^{\circ} \mathrm{C}$ for 45 seconds) $\times 30$, and a final step of $72^{\circ} \mathrm{C}$ for 12 minutes. PCR products were separated onto $1 \%$ agarose gels. $G A P D H$ gene expression was used as an internal control.

\section{C5a Quantification}

Human pulp cells were grown in 12-well plates. At subconfluency, cells were washed three times with PBS and then incubated in $500 \mu \mathrm{L}$ serum-free medium per well with or without lipoteichoic acid (LTA) at $1 \mu \mathrm{g} / \mathrm{mL}$. After 20 minutes, 1 hour, and 24 hours, the supernatants were harvested and C5a concentrations were immediately determined by enzyme-linked immunosorbent assay (ELISA) according to the manufacturer's instructions (DuoSet ELISA development system; R\&D Systems).

\section{Determination of Cell Viability}

Human pulp cells were seeded into 96 -well plates at $3 \times 10^{4}$ cells/well and were incubated overnight to allow cell attachment and recovery. After PBS washing, cells were incubated with $100 \mu \mathrm{L}$ minimal essential medium serumfree with or without $1 \mu \mathrm{g} / \mathrm{mL} \mathrm{LTA}$ and with or without $6 \mu \mathrm{g} / \mathrm{mL}$ soluble CD59, an inhibitor of MAC/C5b-9 formation. After incubation for 2 hours, the supernatants were removed, and $50 \mu \mathrm{g}$ MTT (Sigma-Aldrich) was added to each well and incubated for 2 hours at $37^{\circ} \mathrm{C}$ and $5 \% \mathrm{CO}_{2}$. Supernatants were removed, and $100 \mu \mathrm{L}$ DMSO $100 \%$ was added to each well. For each well, absorbance at $550 \mathrm{~nm}$ was recorded with a microplate reader ( $\Sigma 960$; Metertech, Taipei, Taiwan). Results were expressed as the percent absorbance of each experimental well versus the well containing untreated cells. Three wells per experimental condition were measured in three independent experiments.

\section{C5aR Activation Assay}

Human pulp cells were carefully washed with PBS, and $10^{5}$ cells were incubated for 20 minutes in serum-free minimal essential medium, with or without $1 \mu \mathrm{g} / \mathrm{mL}$ LTA. The supernatants were then harvested and immediately added to
A
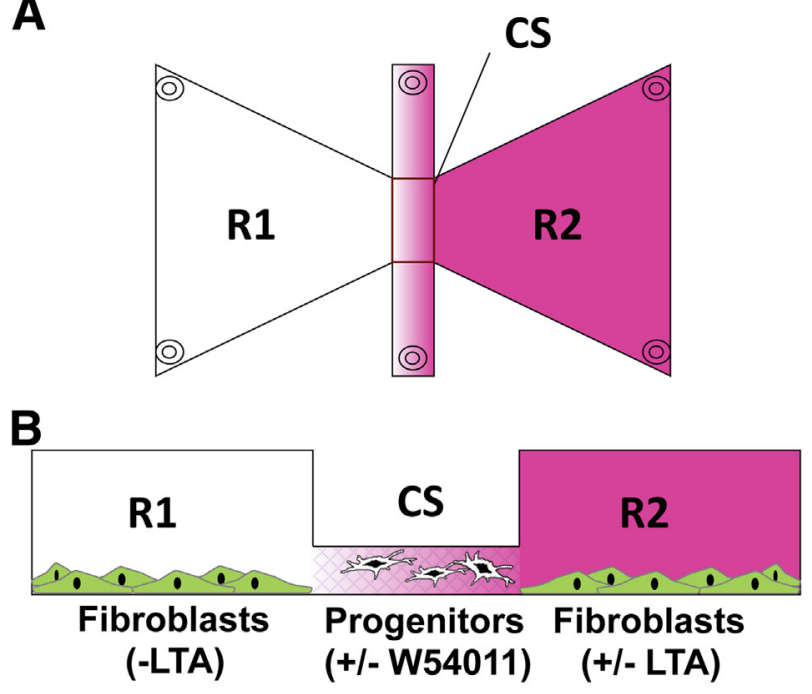

C

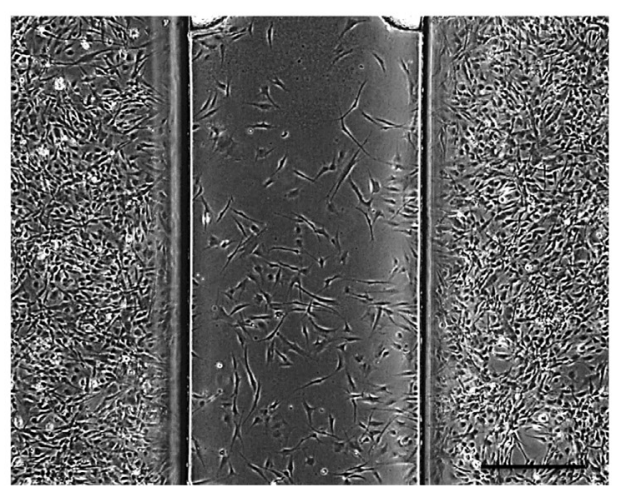

Figure $1 \mu$-Slide 3D chemotaxis assays. A: Reservoirs R1 and R2 communicate with a central thin connecting slit. B: 3D chamber cross section. Human pulp cells were seeded in R1 and R2 with or without LTA, and human progenitor pulp cells were seeded into the connecting slit with or without the C5aR-specific antagonist W54011. C: Direct view of the observation area of the chamber. Migration of progenitor cells in the central slit toward the fibroblasts plated in the lateral reservoirs was monitored for 48 hours. The differential filling of R1 and R2 generates a linear and stable concentration gradient inside the connecting slit. Scale bar $=500 \mu \mathrm{m}$. CS, connecting slit.

human pulp progenitor cells $\left(1 \mathrm{~mL}\right.$ of supernatant per $10^{4}$ progenitor cells), for 5 minutes. Finally, C5aR phosphorylation in human pulp progenitor cells was evaluated by fluorescence microscopy and flow cytometry, as described below for C5aR-p(Ser 334).

\section{Immunofluorescence Staining}

For detection by fluorescence microscopy, pulp progenitor cells and pulp cells were grown in eight-well glass culture chambers to $70 \%$ confluency. For detection by flow cytometry, $10^{6}$ pulp progenitor cells or pulp cells were washed in PBS, trypsinized, and resuspended in $1 \mathrm{~mL}$ of PBS. For both fluorescence microscopy and flow cytometry, cells were rinsed with PBS and fixed with $4 \%$ paraformaldehyde during 15 minutes at $4^{\circ} \mathrm{C}$. Then nonspecific binding sites were blocked with $1 \%$ bovine serum albumin 
for 1 hour, or for intracellular antigen detection, cells were simultaneously permeabilized and saturated with $1 \%$ bovine serum albumin $-0.3 \mathrm{~mol} / \mathrm{L}$ glycine in $0.1 \% \mathrm{PBS}-$ Tween 20 for 1 hour. Cells were incubated for 1 hour with $50 \mu \mathrm{g} / \mathrm{mL}$ primary antibody against C5b-9, $5 \mu \mathrm{g} / \mathrm{mL}$ STRO-1, $2 \mu \mathrm{g} / \mathrm{mL}$ C5aR-p(Ser334), $2 \mu \mathrm{g} / \mathrm{mL}$ fibroblast surface protein (FSP), $2.5 \mu \mathrm{g} / \mathrm{mL}$ CD $44,2.5 \mu \mathrm{g} / \mathrm{mL}$ CD90, $2.5 \mu \mathrm{g} / \mathrm{mL}$ CD105, CD146 $(2.5 \mu \mathrm{g} / \mathrm{mL})$, and $2.5 \mu \mathrm{g} / \mathrm{mL}$ CD166 or the respective isotypes. After washing, the cells were incubated 45 minutes with $2 \mu \mathrm{g} / \mathrm{mL}$ of the respective secondary antibody conjugated with Alexa Fluor 488 or Alexa Fluor 594 and with 1 $\mu \mathrm{g} / \mathrm{mL}$ DAPI counterstain for fluorescence microscopy.

\section{$\mu$-Slide 3D Chamber Chemotaxis Assays}

Pulp progenitor cell migration was analyzed by live cell tracking in $\mu$-Slide chemotaxis three-dimensional (3D) chambers (IBIDI-Biovalley, Marne-la-Vallée, France; Martinsried, Germany). Two reservoirs (R1 and R2) are separated by a thin central connecting slit (Figure 1A). The architecture and dimensions of this chamber generate a linear and stable concentration gradient by diffusing the chemotactic factor within the connecting slit over at least 48 hours. ${ }^{25}$ The manufacturer's instructions were slightly modified and adapted to our migration protocol. For progenitor cells, $2.5 \times 10^{6}$ cells/ $\mathrm{mL}$ were seeded into 1:16 Matrigel/minimal essential medium (BD Biosciences, Bedford, UK; San Jose, CA) within the connecting slit, with or without $10 \mathrm{nmol} / \mathrm{L} \mathrm{W54011,} \mathrm{a}$ specific C5aR antagonist. For pulp cells, $3 \times 10^{7}$ cells $/ \mathrm{mL}$ were seeded into both reservoirs (R1 and R2) in minimal essential medium with or without $1 \mu \mathrm{g} / \mathrm{mL}$ LTA (Figure 1B).

Human progenitor cell migration was monitored under a light microscope (Carl Zeiss Microscopy, Jena, Germany) (Figure 1C); images were captured every 15 minutes over 48 hours. Migrations of 30 to 50 progenitor cells by experiment were tracked manually using the manual tracking plug-in of ImageJ 1.43 software (NIH, Bethesda, MD), and data were analyzed with the IBIDI chemotaxis and migration tool.

For pulp progenitor cell migration investigation within the connecting slit, cell trajectories were extrapolated to $(x ; y)=0$ at time 0 hours, and two values were established for each experiment: the displacement of center of mass (COM) and the forward migration index (FMI). These two parameters have been described previously. ${ }^{25}$ In brief, for each experiment, the COM corresponds to the spatial average of all cell positions ( $x$ and $y$ coordinates). The displacement of COM was calculated as the difference between initial and final COM values. The FMI was calculated in $x$ and $y$ directions as the final endpoint migration divided by the total migration distance. In our experiments, $\mathrm{FMI}_{\mathrm{x}}$ should be higher than $\mathrm{FMI}_{\mathrm{y}}$ if progenitor cells migrate along a gradient.

\section{Statistical Analysis}

All experiments were repeated at least three times, and statistical significance $(P<0.05)$ was determined using the
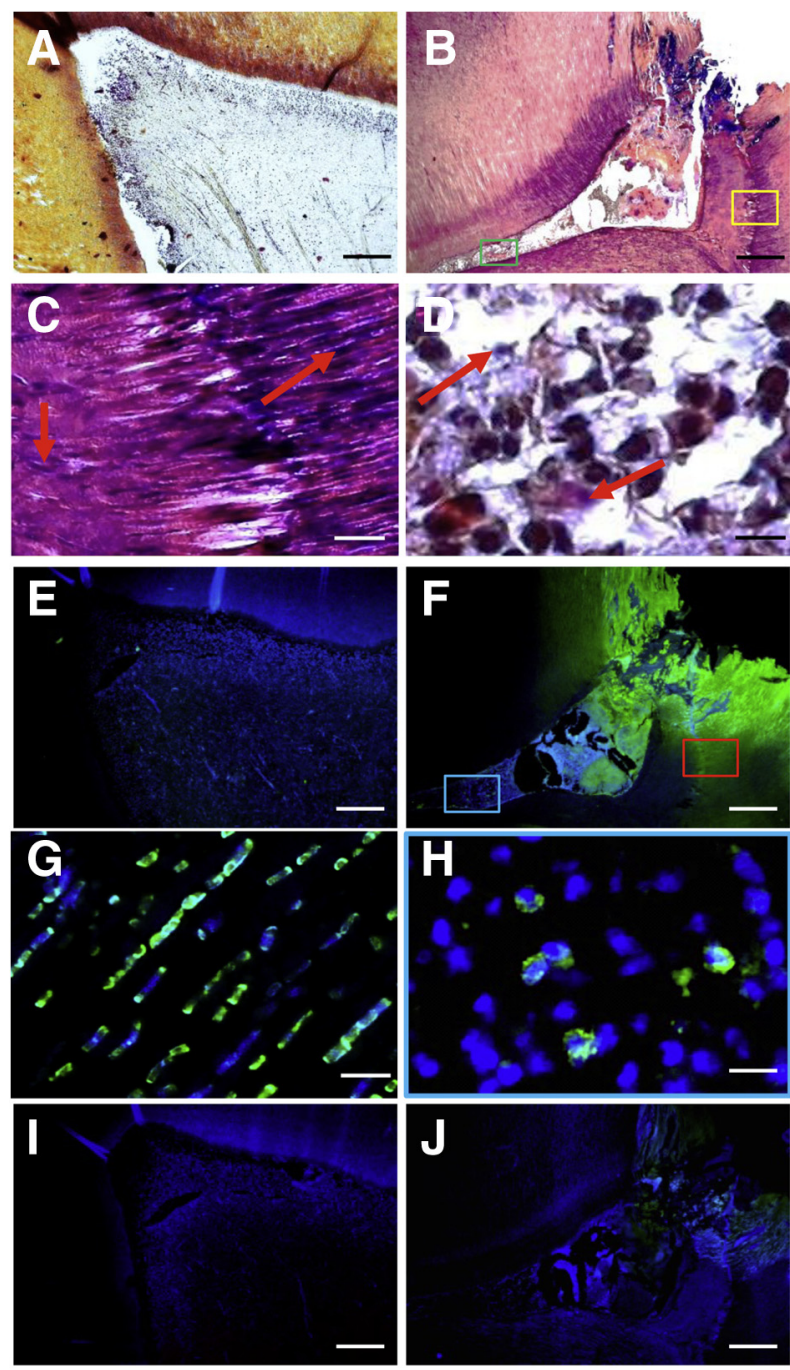

Figure 2 Complement system activation is correlated with Gram-positive bacteria in carious teeth. A-D: Representative images of intact (A) and carious (B-D) teeth (Gram staining). Although no bacteria were detected in intact teeth $(\mathbf{A})$, intense purple labeling indicative of the presence of Grampositive bacteria was observed in carious teeth (B). These bacteria (arrows) are clearly visible at higher magnifications in dentin (C, magnified from the yellow box in B) and pulp tissue (D, magnified from the green box in B). $\mathbf{E}-\mathbf{J}$ : Representative images of MAC immunostaining in noncarious (E) and carious $(\mathbf{F}-\mathbf{H})$ teeth and their respective controls (I and $\mathbf{J})$. MAC formation was not observed in intact teeth $(\mathbf{E})$; in carious teeth, intense MAC labeling indicative of complement system activation was detected (F), which is clearly visible at higher magnification in dentin tubules (G, magnified from the red box in $\mathbf{F})$ and pulp tissue $(\mathbf{H}$, magnified from the blue box in $\mathbf{F})$. Scale bars: $500 \mu \mathrm{m}(\mathbf{A}, \mathbf{B}, \mathbf{E}, \mathbf{F}, \mathbf{I}, \mathbf{J}) ; 20 \mu \mathrm{m}(\mathbf{C}, \mathbf{D}, \mathbf{G}, \mathbf{H})$.

Student's $t$-test to compare the different treatments and their respective controls. Data are expressed as means \pm SD.

\section{Results}

Complement Activation in Vivo Is Correlated with the Presence of Gram-Positive Bacteria

Although no bacteria were detected in intact human tooth sections (Figure 2A), significant numbers of Gram-positive 

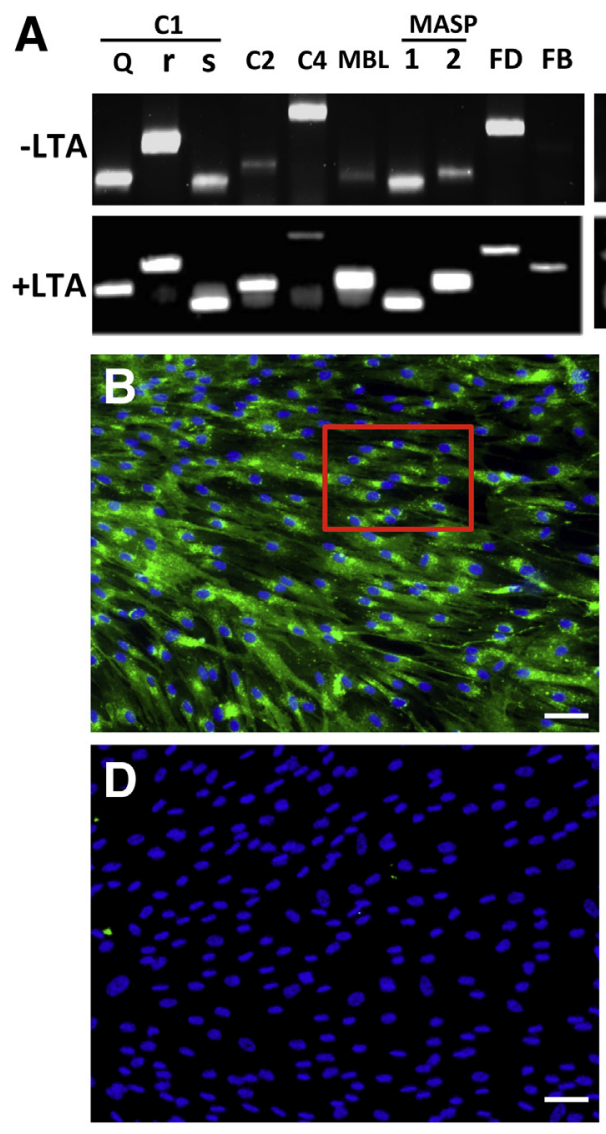
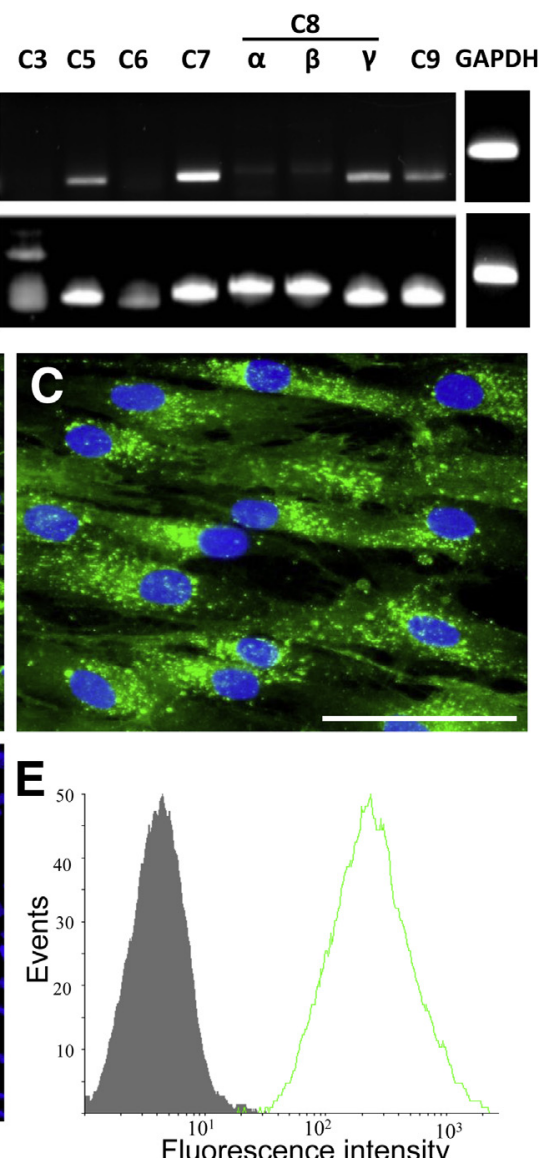

Figure 3 Human pulp fibroblasts stimulated with LTA express all components required for complement system activation. A: RT-PCR product from unstimulated or LTA-stimulated human pulp cells for complement components $\mathrm{C} 1 \mathrm{q}, \mathrm{C} 1 \mathrm{r}, \mathrm{C} 1 \mathrm{~s}, \mathrm{C} 2, \mathrm{C} 4$, MBL, MASP1, MASP2, FD, FB, C3, C5, C6, C7, C8 $\alpha$, $\mathrm{C} 8 \beta, \mathrm{C} 8 \gamma$, and $\mathrm{C} 9$. GAPDH was used as a housekeeping control. In unstimulated pulp cells, $\mathrm{C} 3$ and C6 (two components required for complement system activation) were not detected. By contrast, after LTA stimulation, all complement components were detected, including C3 and C6. B-D: All human pulp cells obtained by the explant outgrowth method express FSP. FSP was detected by immunofluorescence on the surface of all human pulp cells (B), and it is clearly visible at a higher magnification (C), but no immunostaining was observed in control condition with an isotype control (D). Nuclei were counterstained with DAPI (blue). E: Representative flow cytometry histograms of FSP staining performed on human pulp cells obtained by the explant outgrowth method. The fluorescence profile of FSPpositive cells (green) is significantly shifted to the right of the control (gray). $P<0.05 . n=3$. Scale bar $=50 \mu \mathrm{m}$. bacteria were detected in carious tooth sections (Figure 2B). These were observed in dentin tubules, reparative dentin (Figure 2C), and in the underlying pulp tissue (Figure 2D). MAC immunofluorescence staining was used to localize complement activation on the same teeth. Although no complement activation was detected in intact human teeth (Figure 2E), intense labeling was observed at the injured site of carious teeth (Figure 2F). At higher magnification, the presence of MAC in dentin tubules (Figure 2G) and in pulp tissue (Figure $2 \mathrm{H}$ ) was observed. Thus, complement activation in human carious teeth is correlated with the presence of Gram-positive bacteria in the dentin and pulp.

\section{Human Pulp Fibroblasts Stimulated with Lipoteichoic Acid Express All Components Required for Complement Activation}

To examine the effect of Gram-positive bacteria on protein complement expression, human pulp cells were cultured without serum for 1 hour, in the presence or absence of 1 $\mu \mathrm{g} / \mathrm{mL}$ LTA. In cells were not treated with LTA, neither C3 nor C6 (two essential components to complement system activation) were detected by RT-PCR analysis (Figure 3A). However, in pulp cells incubated with LTA for 1 hour, all components required for complement activation were expressed, including C3 and C6 components (Figure 3A).
FSP staining analysis by immunofluorescence microscopy (Figure 3, B-D) and flow cytometry (Figure 3E) showed that all pulp cells used in these experiments by the explant outgrowth method were fibroblasts (Figure 3F), and hereafter these cells are designated as pulp fibroblasts. These results demonstrated that, under LTA stimulation, human pulp fibroblasts express all complement components.

\section{LTA Stimulation of Human Pulp Fibroblasts Leads to Functional MAC Production}

To determine whether the complement proteins expressed by human pulp fibroblasts after LTA stimulation were functional, we tested complement activation in terms of MAC formation under serum-free conditions. Although no MAC formation was detected on untreated fibroblasts (Figure 4A), intense labeling was observed on human pulp fibroblasts after 1 hour of stimulation with LTA (Figure 4, B and F). The binding of MAC on human pulp fibroblasts after stimulation with LTA was reflected by a significant staining decrease on coincubation of the cells with the soluble CD59 used as a MAC formation inhibitor (Figure 4,C and D). This result was correlated with MTT assay performed on human pulp fibroblasts under the same conditions (Figure 4G). The number of living cells detected after coincubation of pulp fibroblasts simultaneously with both CD59 and LTA was significantly higher $(P<0.05)$ than that detected after incubation with LTA only (Figure $4 \mathrm{G}$ ). 

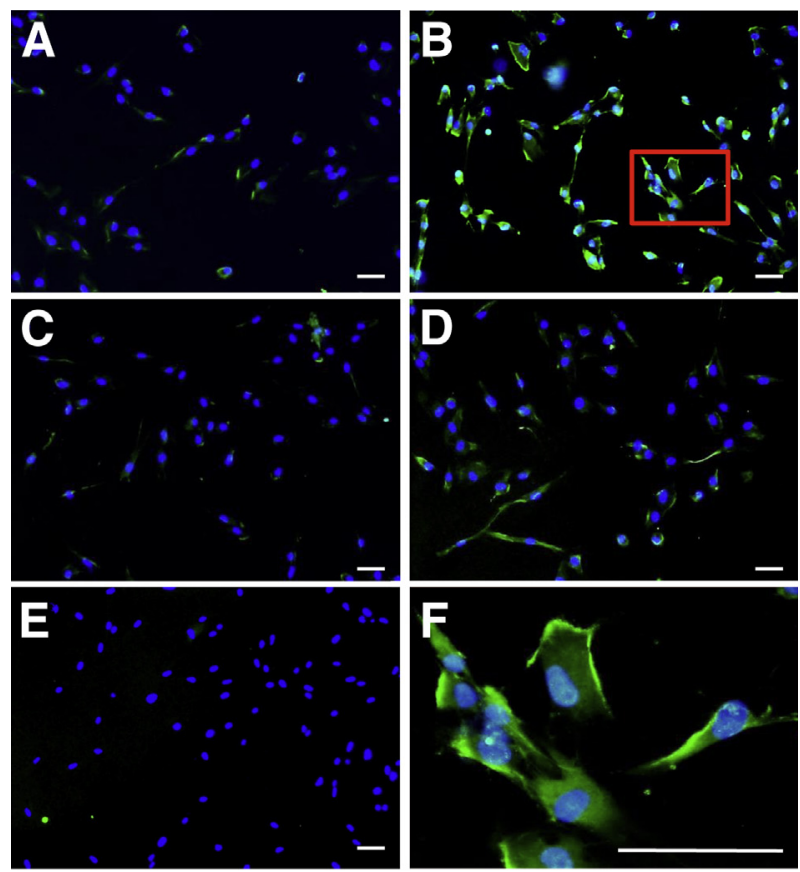

G 120

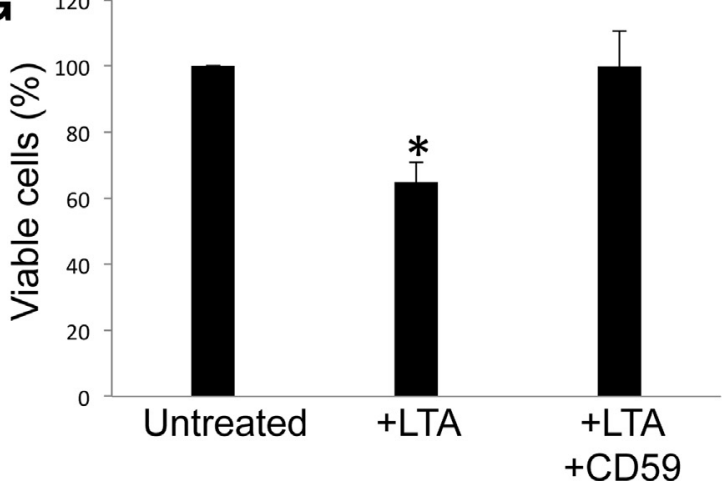

Figure 4 LTA stimulation of human pulp fibroblasts leads to production of functional MAC. A-F: Representative images of MAC immunostaining on unstimulated ( $\mathbf{A}$ and $\mathbf{C})$ or LTA-stimulated (B, D, E and $\mathbf{F})$ pulp fibroblasts in the presence ( $\mathbf{C}$ and $\mathbf{D})$ or absence ( $\mathbf{A}$ and $\mathbf{B}$ ) of soluble CD59, an inhibitor of MAC formation. Although no MAC was observed on unstimulated pulp fibroblasts (A and $\mathbf{C}$ ), intense MAC labeling, corresponding to complement system activation, was detected on LTA-stimulated pulp fibroblasts (B) and is clearly visible at a higher magnification $(\mathbf{F})$. The incubation of pulp fibroblasts with soluble CD59 drastically inhibited MAC formation on LTAstimulated fibroblasts (D). Nuclei were counterstained with DAPI (blue). G: The viability of LTA-stimulated and unstimulated pulp fibroblasts was determined by MTT assay. For each experiment, the viability of untreated pulp fibroblasts was set at $100 \%$. LTA treatment significantly decreased pulp fibroblast viability $(66.9 \pm 6.6 \%)$. This significant difference was abolished by incubation of pulp fibroblasts with soluble CD59 $(95.7 \pm 10.8 \%)$. Scale bar $=50 \mu \mathrm{m} .{ }^{*} P<0.05 . n=3$ per group.

\section{Complement System Activation from Components Produced by Human Pulp Fibroblasts after LTA Stimulation Leads to C5a Generation}

Having demonstrated that LTA stimulation induces complement activation from complement components produced by human pulp fibroblasts, we studied the ability of this complement activation to generate the $\mathrm{C} 5 \mathrm{a}$ active fragment. Our results obtained by ELISA assay demonstrated that LTA stimulation of human pulp fibroblast leads to a quick and significant $(P<0.05)$ increase of C5a release in the culture medium after 20 minutes (Figure 5). C5a concentration later returned to control values; no significant differences were detected between untreated and LTA-stimulated cells after 1 or 24 hours (Figure 5).

\section{C5a Generated by Human Pulp Fibroblasts after LTA Stimulation Activates the C5aR of Human Pulp Progenitor Cells}

To study the interaction between pulp progenitor cells and pulp fibroblasts, the former were isolated from human pulp cells by STRO-1 magnetic sorting. To ensure a high quality and purity of the progenitor cells obtained by this method, we performed immunostaining of six stem-cell markers (Figure 6). As expected, flow cytometry and fluorescent microscopy analyses revealed that significant numbers of cells obtained by STRO-1 magnetic cell sorting $(P<0.05)$ expressed STRO-1 (Figure 6, A and B). As demonstrated by flow cytometry (Figure 6C), cells obtained by STRO-1 magnetic cell sorting also express the stem-cell markers CD44, CD90, CD105, CD146 and CD166. The coexpression of these stem-cell markers and STRO-1 by sorted cells was clearly visible under fluorescence microscopy (Figure 6D).

The efficiency of C5a generated by human pulp fibroblast after LTA stimulation was tested for its capacity to activate the C5aR expressed by pulp progenitor cells. C5aR activation is correlated with phosphorylation of its serine 334 . When these progenitor cells were incubated with untreated pulp fibroblast culture supernatants, no significant C5aR phosphorylation was detected (Figure 7A). However, when pulp progenitor cells were incubated for 2 minutes with LTA-stimulated pulp fibroblast culture supernatants, significant $\mathrm{C} 5 \mathrm{aR}$ phosphorylation was observed by fluorescent microscopy (Figure 7B) and flow cytometry (Figure 7E).

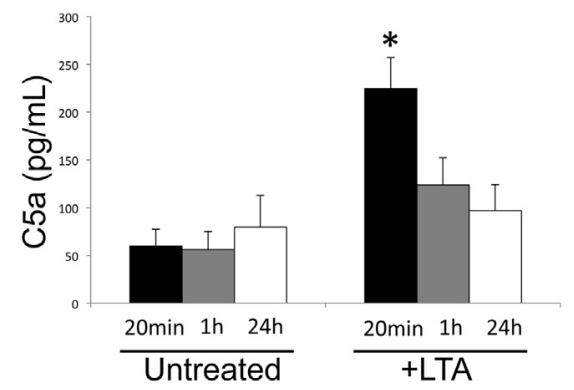

Figure 5 C5a complement fragment is detected in human pulp fibroblast supernatants after 20 minutes of LTA stimulation. Although nonsignificant quantities of $\mathrm{C} 5 \mathrm{a}$ were detected in the supernatant of untreated cells, LTA stimulation of pulp fibroblast for 20 minutes led to a significant increase of $\mathrm{C} 5 \mathrm{a}$ in the supernatant $(224.8 \pm 32.5 \mathrm{pg} / \mathrm{mL}$ versus $59.8 \pm 17.7$ $\mathrm{pg} / \mathrm{mL}$ ). C5a concentration decreased after longer periods, and no statistically significant difference was found between LTA-stimulated and unstimulated cells after 1 or 24 hours. ${ }^{*} P<0.05 . n=3$ per group. 
A

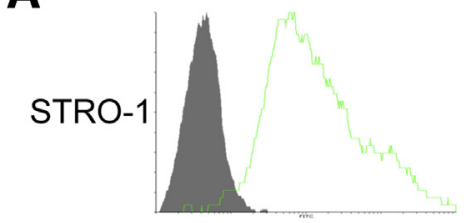

C

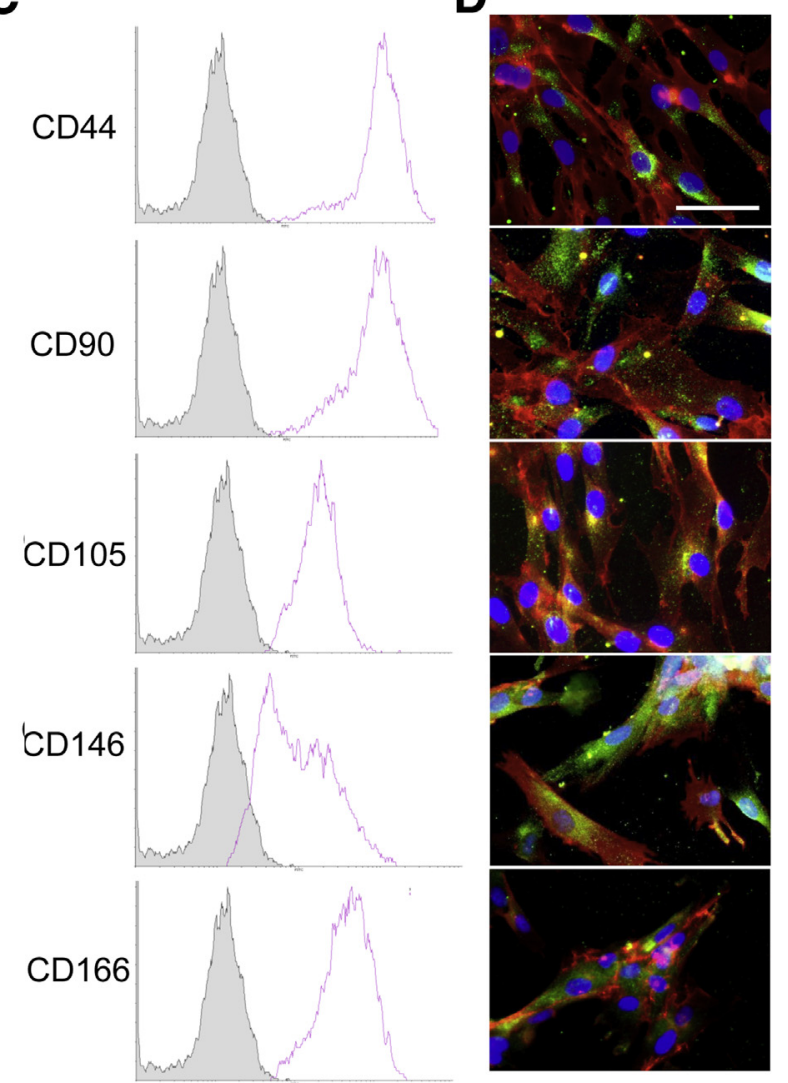

Figure 6 Characterization of STRO-1 sorted cells by flow cytometry and fluorescence microscopy. A and B: In contrast to the control (A, gray), almost all human pulp cells sorted with STRO-1 antibody expressed this mesenchymal stem-cell marker (A, green profile; B, green staining). Nuclei were counterstained with DAPI (blue). C and D: In contrast to the isotype control (C, gray), a significant percentage of STR0-1 sorted human pulp cells (C, red profiles; $\mathbf{D}$, red staining) expressed the stem-cell markers CD44, CD90, CD105, CD146, and CD166 $(P<0.05)$. Fluorescence double immunostaining was used to detect coexpression of these markers by STR0-1 sorted cells. Secondary antibodies used to detect STRO-1 were conjugated with Alexa Fluor 488 (green); the other stem-cell markers were detected with Alexa Fluor 594 (red). Nuclei were counterstained with DAPI (blue). Scale bar $=50 \mu \mathrm{m}$.

\section{C5a Release by LTA-Stimulated Pulp Fibroblasts Induces Pulp Progenitor Cell Recruitment}

Human progenitor cell displacements are presented as -LTA and +LTA trajectories (Figure 8, A-C). When human pulp fibroblasts of the two lateral reservoirs were not stimulated with LTA, the pulp progenitor cells movements in the central connecting slit were random (Figure 8A). However, when pulp fibroblasts of one of the lateral reservoirs were stimulated with LTA, pulp progenitor cells moved sharply toward the
LTA-stimulated fibroblasts (Figure 8B). This migration was markedly decreased when progenitor cells were coincubated with the C5aR-specific antagonist W54011 (Figure 8C).

As expected, pulp progenitor cell migration analysis confirmed these trajectory observations (Figure 8, D-F). No statistically significant COM displacement in the $x$ or $y$ direction was detected without LTA stimulation of human pulp fibroblasts (Figure 8D), but a statistically significant shift of COM $(P<0.05)$ toward LTA-stimulated fibroblasts was observed (Figure 8E). This shift was suppressed by incubation of human pulp progenitor cells with W54011
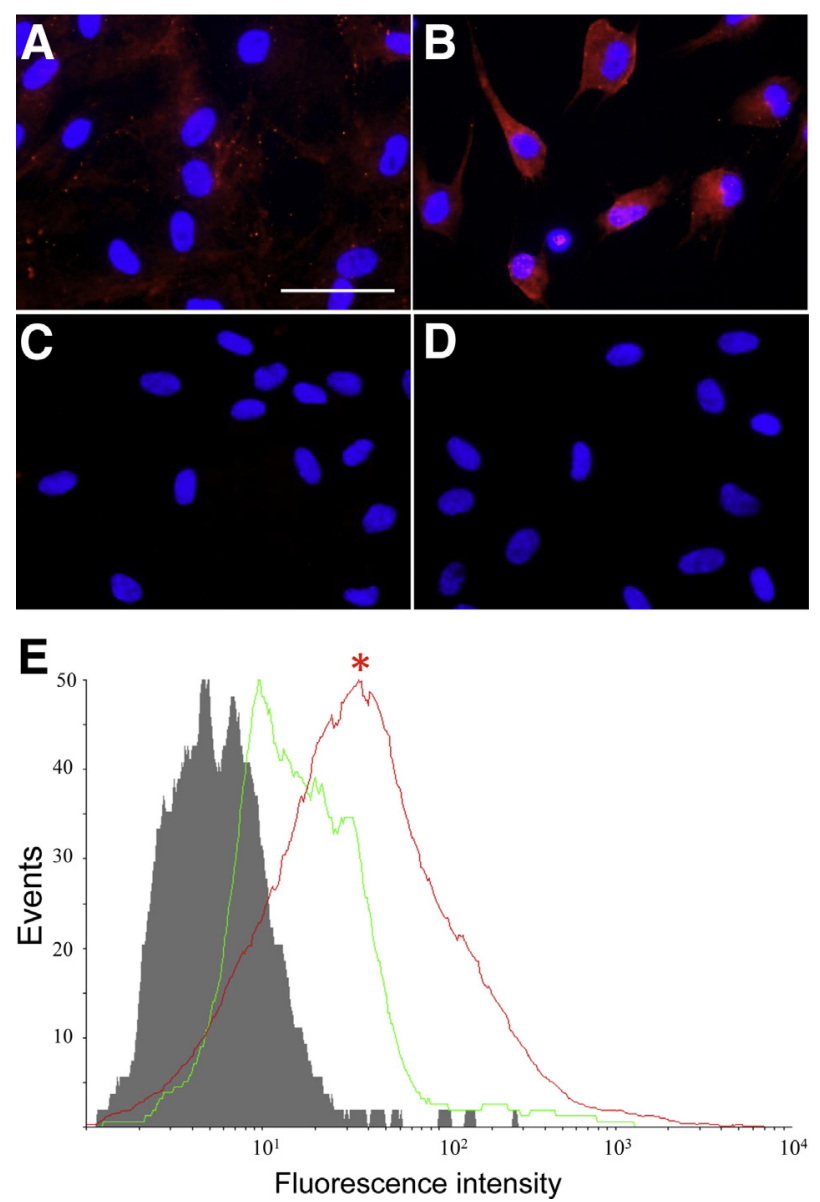

Figure 7 C5a generated by LTA-stimulated pulp fibroblasts activates human pulp progenitor cell C5aR. A-D: Representative images of activated C5aR [C5aR-p(Ser334)] immunostaining on human pulp progenitor cells incubated either with untreated $(\mathbf{A})$ or with LTA-stimulated pulp fibroblast culture supernatants (B) and their respective isotype controls (C and D). Although no activation of $\mathrm{C} 5 \mathrm{aR}$ was detected on progenitor cells incubated with supernatants from untreated pulp fibroblast cultures (A), intense labeling was observed on progenitor cells after incubation with supernatants obtained from LTA-stimulated pulp fibroblast cultures (B). Nuclei were counterstained with DAPI (blue). E: Representative flow cytometry graph of activated C5aR immunostaning on human pulp progenitor cells incubated either with supernatants from untreated pulp fibroblast cultures (green profile) or with supernatants from LTA-stimulated pulp fibroblast cultures (red profile), and the respective control (gray). Only the fluorescence profiles of progenitor cells stimulated with supernatants from LTAstimulated pulp fibroblast cultures are significantly shifted to the right. ${ }^{*} P<0.05 . n=3$. Scale bar $=50 \mu \mathrm{m}$. 


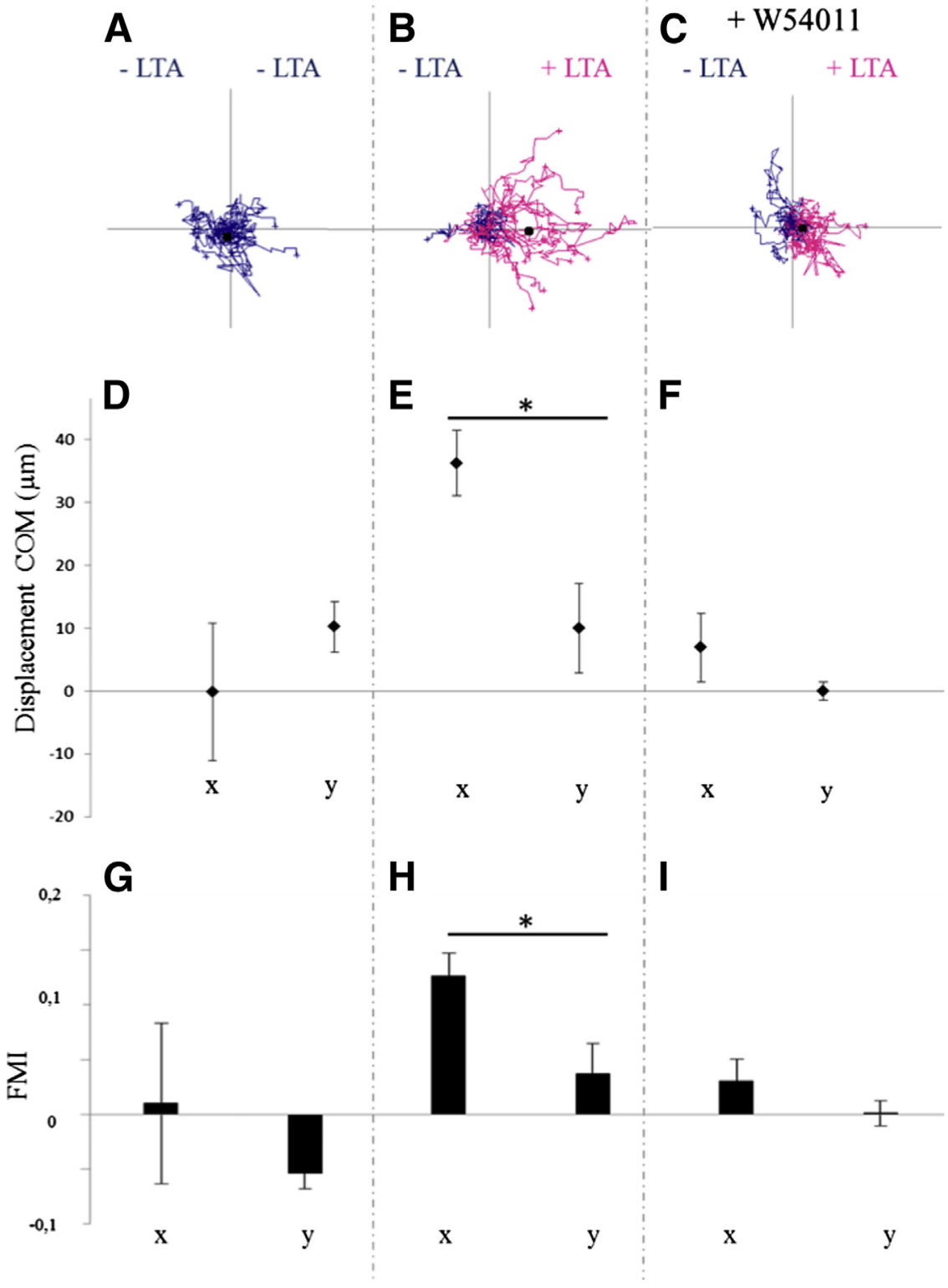

Figure 8 C5a released by LTA-stimulated pulp fibroblasts induces human pulp progenitor cell recruitment. A: Representative plots of progenitor cell migration over 48-hour period. No directed migration was detected in the absence of LTA stimulation, and the COM (circle) remains in the middle of the plot. B: When fibroblasts of one of the two reservoirs were stimulated with LTA, the progenitor cells migrated toward the LTA-stimulated fibroblasts; the COM (circle) is shifted toward the $x$-axis positive direction. C: Coincubation of progenitor cells with W54011 abolished their migration toward the LTA-stimulated fibroblasts, and the COM (circle) returns to the middle of the plot. D-F: Analysis of the center of mass displacement. D: Graphing the $\operatorname{COM} x$ and $y$ means for each dynamic chemotaxis assay revealed no significant differences between $\mathrm{COM}_{x}$ and $\mathrm{COM}_{y}$ in the absence of fibroblast LTA stimulation $\left(\mathrm{COM}_{\mathrm{x}}=-0.1 \pm 10.9 \mu \mathrm{m}\right.$; $\left.\mathrm{COM}_{\mathrm{y}}=10.2 \pm 4.0 \mu \mathrm{m}\right)$, reflecting random cell movements. E: When fibroblasts of one of the two reservoirs were stimulated with LTA, there was a significant difference between $\mathrm{COM}_{\mathrm{x}}$ and $\mathrm{COM}_{\mathrm{y}}$ $\left(\mathrm{COM}_{\mathrm{x}}=36.3 \pm 5.2 \mu \mathrm{m}, \mathrm{COM}_{\mathrm{y}}=10.0 \pm 7.0 \mu \mathrm{m}\right)$, indicating a statistically significant displacement of progenitor cells toward LTA stimulation. F: This significant difference between $\mathrm{COM}_{\mathrm{x}}$ and $\mathrm{COM}_{\mathrm{y}}$ was abolished by W54011 $\left(\mathrm{COM}_{\mathrm{x}}=6.9 \pm 5.5 \mu \mathrm{m}\right.$; $\left.\mathrm{COM}_{\mathrm{y}}=-0.0 \pm 1.4 \mu \mathrm{m}\right)$. G-I: FMI analysis. G: Histograms representing the $F \mathrm{FI}_{x}$ and $\mathrm{FMI}_{\mathrm{y}}$ means for each dynamic chemotaxis assay, show no significant differences between $\mathrm{FMI}_{x}$ and $\mathrm{FMI}_{\mathrm{y}}$ in the absence of fibroblast LTA stimulation. $\mathrm{H}$ : When fibroblasts of one of the two reservoirs were stimulated with LTA, $F M I_{x}$ was significantly higher than $F M I_{y}$ $\left(\right.$ FMI $\left._{\mathrm{x}}=0.13 \pm 0.02 \mu \mathrm{m} ; \mathrm{FMI}_{\mathrm{y}}=0.04 \pm 0.03 \mu \mathrm{m}\right)$, indicating that progenitor cell displacement is along a gradient. I: This significant difference between $\mathrm{FMI}_{x}$ and $\mathrm{FMI}_{\mathrm{y}}$ was abolished by W54011, indicating that progenitor cells migrate toward a C5a gradient generated by LTA-stimulated fibroblasts (I). Data are expressed as means $\pm \mathrm{SD}(\mathbf{D}-\mathbf{I}) .{ }^{*} P<0.05 . n=3$.

(Figure 8F). Thus, C5a generated after stimulation of pulp fibroblasts with LTA induced a specific and significant migration of human pulp progenitor cells.

Moreover, FMI analysis of pulp progenitor cell migration revealed that the $\mathrm{FMI}_{\mathrm{x}}$ toward pulp fibroblasts stimulated with LTA was significantly higher than the $\mathrm{FMI}_{\mathrm{y}}(P<0.05)$ (Figure $8 \mathrm{H}$ ), indicating that human pulp progenitor cells migrate along the $\mathrm{C} 5 \mathrm{a}$ gradient.

\section{Discussion}

The main outcome of this work is the demonstration that pulp fibroblasts produce all components required for efficient complement activation leading both to formation of the cytolytic MAC formation and to release of the biologically active C5a fragment. The C5a, released as a result of fibroblast stimulation by LTA, interacts with C5aR expressed by pulp progenitor cells and induces their recruitment in a gradient-dependent manner. ${ }^{23}$ Our findings demonstrate that complement system activation is correlated with the presence of Gram-positive bacteria in carious dentin and pulp tissues, as revealed by MAC formation and Gram staining on carious teeth sections in vivo. Complement activation in infected tissues is recognized as an innate immune defense mechanism due mainly to circulating complement proteins. ${ }^{3}$ After induction with pathogen components, complement activation leads to the formation of MAC on the pathogen surface and lysis. ${ }^{26,27}$

In the present study, we demonstrated by RT-PCR that, in the absence of stimulation, human pulp fibroblasts strongly express several complement proteins. The detected RNAs, such as those of $\mathrm{C} 4, \mathrm{C} 1$, or $\mathrm{FD}$, correspond to the components responsible for initiating complement activation by different pathways. This suggests that fibroblasts generate a pool of 
proteins directly available to quickly react against infection, thus optimizing local complement activation. Interestingly, after stimulation with LTA, which is a complex component of Gram-positive bacteria cell walls, human pulp fibroblasts expressed all of the proteins required for efficient complement activation, including components common to the three complement activation pathways, such as $\mathrm{C} 3$ and C6. This suggests a local regulation of complement activation within the pulp. Indeed, after stimulation with LTA, MAC formation, which is the ultimate step of complement system activation, was detected on pulp fibroblasts and led to a significant decrease in their viability. This result is in accord with previous investigations demonstrating odontoblast and pulp cell death in carious teeth by apoptosis. ${ }^{28}$ In the present study, these findings were obtained in vitro only, because of the absence of plasma complement regulation components in the culture medium. Adding the soluble CD59 MAC formation inhibitor to the LTA-stimulated cells significantly reduced MAC formation on their surface and increased their viability to the level of unstimulated cells.

Several previous studies have clearly demonstrated that a variety of nonimmune cells produce some soluble proteins of the complement system, either constitutively or as a response to stimuli. However, this extrahepatic synthesis seems to simply optimize the plasmatic complement system activation. ${ }^{7}$ The part of our study performed in vitro was realized in serum-free conditions, to avoid the presence of any plasmatic complement component. This part was performed on adherent cells from the explant outgrowth method. ${ }^{24}$ Although a mixed population could be obtained by this method, both immunofluorescence and flow cytometry with antibodies to fibroblast surface protein antigen showed that the cells used in these experiments were fibroblasts. The present study is, to our knowledge, the first to identify the human pulp fibroblast as a unique nonimmune cell type able to produce and efficiently activate its own complement components.

Although the expression of complement proteins was investigated only in pulp fibroblasts, this does not exclude their expression in other pulp cell types. The dental pulp is composed of heterogeneous cell populations that include fibroblasts, odontoblasts, pericytes, endothelial cells, smooth muscle cells, progenitor and stem cells, among others. Fibroblasts, however, represent the major cell population within the pulp tissue. Although the synthesis of complement proteins by other pulp cell types was beyond our present scope, we speculate that such synthesis might further increase the efficiency of complement activation within the pulp.

Moreover, complement system activation from proteins expressed by LTA-stimulated pulp fibroblasts is also translated by the C5a complement fragment release into the culture medium. It has been demonstrated that the active C5a fragment is highly implicated in tissue regeneration. ${ }^{29-33} \mathrm{In}$ particular, we have previously demonstrated that recombinant C5a induces the recruitment of dental pulp progenitor cells, which is an essential step in dentin pulp regeneration. ${ }^{23}$
However, no other study has yet shown the importance of the extrahepatic production of complement components in tissue regeneration. To study the effect of pulp fibroblasts on progenitor cell migration, we used a dynamic system with $\mu$ Slide chemotaxis 3D chambers, which allows investigating interactions between pulp fibroblasts and progenitor cells in a plasma-free environment. Pulp progenitors were obtained by STRO-1 magnetic cell sorting. The isolated cells were further tested for coexpression of STRO-1 mesenchymal stem-cell marker and for other stem-cell markers (CD44, CD90, CD105, CD146, CD166) by immunofluorescence and flow cytometry. This system clearly demonstrated that the C5a generated by complement system activation from components produced directly by LTA stimulation of pulp fibroblasts induced the recruitment of human pulp progenitor cells within the migration chamber in a plasma-free environment. This recruitment is mediated by fixation of C5a on progenitor $\mathrm{C} 5 \mathrm{aR}$, as demonstrated by the phosphorylation of C5aR after C5a fixation detected by immunofluorescence and flow cytometry, and by the decrease of this phosphorylation when progenitor cells were incubated with the C5aR-specific antagonist W54011. These results suggest that the efficiency of the plasma complement system in progenitor cell recruitment is locally potentiated by human pulp fibroblasts.

The present study provides further evidence of efficient interactions between pulp fibroblasts and progenitor cells during dentin-pulp regeneration and provides additional support to previous investigations of pulp fibroblast involvement in dentin pulp regeneration. Human pulp fibroblasts increase their growth factor secretion after traumatic injury, leading to a modification of the local microenvironment, which has direct consequences on the local dentinpulp regeneration. ${ }^{20-22}$ This regeneration, which occurs after dentin-pulp injuries, is regulated by several signals from two distinct and local origins. These signals are liberated after an acid dissolution of the carious dentin, ${ }^{14,17,18}$ or are released from pulp fibroblasts and endothelial cells in the case of traumatic injuries. ${ }^{19,20}$ Recently, the complement system has been revealed as an additional source of regeneration signals. ${ }^{23}$ Studies performed in our laboratory demonstrated that the complement system is activated in human teeth by carious injuries and that recombinant C5a induces recruitment of dental pulp progenitor cells, which is an essential step of the dentin-pulp regeneration. ${ }^{23}$ Because all dentin-pulp insults (including carious infection, traumatic injuries, apoptosis, and the application of restorative materials) are known activators of the complement system, ${ }^{8-11}$ the present study supports the current idea that, like other regeneration signals, complement activation within the dentin-pulp complex is locally activated and regulated.

To our knowledge, the present work is the first to identify a nonimmune cell able to produce all components required for efficient complement system activation. Our findings highlight a new mechanism in dentin-pulp regeneration, linking pulp fibroblast to human pulp progenitor cell recruitment, and may provide a useful therapeutic tool in 
targeting the pulp fibroblasts in a dentin-pulp regeneration process.

\section{Acknowledgment}

We thank Dr. Jean-Charles Gardon for providing the third molars and Charles Prévôt for technical assistance with flow cytometry (INSERM CRO2, Marseille, France).

\section{References}

1. Basiglio CL, Arriaga SM, Pelusa F, Almará AM, Kapitulnik J, Mottino AD: Complement activation and disease: protective effects of hyperbilirubinaemia. Clin Sci 2010, 118:99-113

2. Sarma JV, Ward PA: The Complement System. Cell Tissue Res 2011, 343:227-235

3. Walport MJ: Complement. N Engl J Med 2001, 344:1058-1066

4. Ricklin D, Hajishengallis G, Yang K, Lambris JD: Complement: a key system for immune surveillance and homeostasis. Nat Immunol 2010, 11:785-797

5. Alper CA, Johnson AM, Birtch AG, Moore FD: Human C'3: evidence for the liver as the primary site of synthesis. Science 1969, 163:286-288

6. Würzner R: Modulation of complement membrane attack by local C7 synthesis. Clin Exp Immunol 2000, 121:8-10

7. Li K, Sacks SH, Zhou W: The relative importance of local and systemic complement production in ischaemia, transplantation and other pathologies. Mol Immunol 2007, 44:3866-3874

8. Andersson J, Ekdahl KN, Lambris JD, Nilsson B: Binding of C3 fragments on top of adsorbed plasma proteins during complement activation on a model biomaterial surface. Biomaterials 2005, 26:1477-1485

9. Lynch NJ, Roscher S, Hartung T, Morath S, Matsushita M, Maennel DN Kuraya M, Fujita T, Schwaeble WJ: L-ficolin specifically binds to lipoteichoic acid, a cell wall constituent of Gram-positive bacteria, and activates the lectin pathway of complement. J Immunol 2004, 172:1198-1202

10. Moosig F, Damm F, Knorr-Spahr A, Ritgen M, Zeuner RA, Kneba M, Ernst M, Schroder JO: Reduced expression of C1q-mRNA in monocytes from patients with systemic lupus erythematosus. Clin Exp Immunol 2006, 146:409-416

11. Verhoven B, Schlegel RA, Williamson P: Mechanisms of phosphatidylserine exposure, a phagocyte recognition signal, on apoptotic T lymphocytes. J Exp Med 1995, 182:1597-1601

12. Shivakumar KM, Vidya SK, Chandu GN: Dental caries vaccine. Indian J Dent Res 2009, 20:99-106

13. Goldberg M, Farges JC, Lacerda-Pinheiro S, Six N, Jegat N, Decup F Septier D, Carrouel F, Durand S, Chaussain-Miller C, Denbesten P, Veis A, Poliard A: Inflammatory and immunological aspects of dental pulp repair. Pharmacol Res 2008, 58:137-147

14. Smith AJ, Tobias RS, Cassidy N, Bégue-Kirn C, Ruch JV, Lesot H: Influence of substrate nature and immobilization of implanted dentin matrix components during induction of reparative dentinogenesis. Connect Tissue Res 1995, 32:291-296

15. Shi S, Gronthos S: Perivascular niche of postnatal mesenchymal stem cells in human bone marrow and dental pulp. J Bone Miner Res 2003 18:696-704
16. Téclès $\mathrm{O}$, Laurent $\mathrm{P}$, Zygouritsas $\mathrm{S}$, Burger AS, Camps J, Dejou J, About I: Activation of human dental pulp progenitor/stem cells in response to odontoblast injury. Arch Oral Biol 2005, 50:103-108

17. Smith AJ, Tobias RS, Cassidy N, Plant CG, Browne RM, BegueKirn C, Ruch JV, Lesot H: Odontoblast stimulation in ferrets by dentine matrix components. Arch Oral Biol 1994, 39:13-22

18. Graham L, Cooper PR, Cassidy N, Nor JE, Sloan AJ, Smith AJ: The effect of calcium hydroxide on solubilisation of bio-active dentine matrix components. Biomaterials 2006, 27:2865-2873

19. About I: Dentin regeneration in vitro: the pivotal role of supportive cells. Adv Dent Res 2011, 23:320-324

20. Tran-Hung L, Laurent P, Camps J, About I: Quantification of angiogenic growth factors released by human dental cells after injury. Arch Oral Biol 2008, 53:9-13

21. About I: Dentin-pulp regeneration: the primordial role of the microenvironment and its modification by traumatic injuries and bioactive materials. Endod Top 2013, 28:61-89

22. Laurent $\mathrm{P}$, Camps J, About I: Biodentine(TM) induces TGF- $\beta 1$ release from human pulp cells and early dental pulp mineralization. Int Endod J 2012, 45:439-448

23. Chmilewsky F, Jeanneau C, Laurent P, Kirschfink M, About I: Pulp progenitor cell recruitment is selectively guided by a C5a gradient. J Dent Res 2013, 92:532-539

24. About I, Bottero MJ, de Denato P, Camps J, Franquin JC, Mitsiadis TA Human dentin production in vitro. Exp Cell Res 2000, 258:33-41

25. Zengel P, Nguyen-Hoang A, Schildhammer C, Zantl R, Kahl V, Horn E: $\mu$-Slide Chemotaxis: a new chamber for long-term chemotaxis studies. BMC Cell Biol 2011, 12:21

26. Haeney MR: The role of the complement cascade in sepsis. J Antimicrob Chemother 1998, 41(Suppl A):41-46

27. Kenneth M, Travers P, Walport M, Janeway C: Janeway's immunobiology. ed 8. New York, Garland Science, 2012, pp 48-71

28. Mitsiadis TA, de Bari C, About I: Apoptosis in developmental and repair-related human tooth remodeling: a view from the inside. Exp Cell Res 2008, 314:869-877

29. Ignatius A, Schoengraf P, Kreja L, Liedert A, Recknagel S, Kandert S Brenner RE, Schneider M, Lambris JD, Huber-Lang M: Complement $\mathrm{C} 3 \mathrm{a}$ and $\mathrm{C} 5 \mathrm{a}$ modulate osteoclast formation and inflammatory response of osteoblasts in synergism with IL-1 $\beta$. J Cell Biochem 2011, 112:2594-2605

30. Lara-Astiaso D, Izarra A, Estrada JC, Albo C, Moscoso I, Samper E, Moncayo J, Solano A, Bernad A, Díez-Juan A: Complement anaphylatoxins $\mathrm{C} 3 \mathrm{a}$ and $\mathrm{C} 5 \mathrm{a}$ induce a failing regenerative program in cardiac resident cells. Evidence of a role for cardiac resident stem cells other than cardiomyocyte renewal. Springerplus 2012, 1:63

31. Mastellos D, Papadimitriou JC, Franchini S, Tsonis PA, Lambris JD: A novel role of complement: mice deficient in the fifth component of complement (C5) exhibit impaired liver regeneration. J Immunol 2001, 166:2479-2486

32. Schraufstatter IU, DiScipio RG, Zhao M, Khaldoyanidi SK: C3a and C5a are chemotactic factors for human mesenchymal stem cells, which cause prolonged ERK1/2 phosphorylation. J Immunol 2009, 182 3827-3836

33. Strey CW, Markiewski M, Mastellos D, Tudoran R, Spruce LA, Greenbaum LE, Lambris JD: The proinflammatory mediators C3a and C5a are essential for liver regeneration. J Exp Med 2003, 198: 913-923 